\title{
Prevalence of cesarean section on demand in Assiut Governorate, Egypt
}

\author{
Mahmoud S. Zakherah'1, Tarek A. Farghaly' ${ }^{1}$ Elham S. Ahmed², Ahmed M. Abbas ${ }^{1 *}$
}

\author{
${ }^{1}$ Department of Obstetrics and Gynecology, Faculty of Medicine, Assiut University, Assiut, Egypt \\ ${ }^{2}$ Department of Obstetrics and Gynecology, Abnob Hospital, Assiut, Egypt
}

Received: 31 January 2019

Accepted: 06 March 2019

\section{*Correspondence:}

Dr. Ahmed M. Abbas,

E-mail: bmr90@hotmail.com

Copyright: (C) the author(s), publisher and licensee Medip Academy. This is an open-access article distributed under the terms of the Creative Commons Attribution Non-Commercial License, which permits unrestricted non-commercial use, distribution, and reproduction in any medium, provided the original work is properly cited.

\section{ABSTRACT}

Background: The current study aims to evaluate the prevalence of CS on demand in Women's health hospital, Assiut University and Abnob Central Hospital in Assiut Governorate, Egypt.

Methods: A cross sectional study conducted in Assiut Women Health Hospital and Abnob central hospital from January 2017 to December 2017. The total number of cesarean section done was 180 cases and the number of CS on demand was $64(35.6 \%)$. The demographic data were collected by one of the study investigators. Women were asked about the causes of requesting CS before surgery.

Results: The study group was 64 women with age ranging from 18-40 years old, 40 primipara and 24 multipara. Of those 24 women, 21 of them previously delivered vaginally and only 3 women delivered by emergency CS. Twentysix women had a history of previous abortion. Fear of pain was the main cause for CS on demand in the whole study participants (57.8\%). In primipara, the main cause for requesting CS is fear of pain in $62.5 \%$ of participants followed by fear on the baby in $45 \%$ of women. On the other hand, in multipara, the main cause for CS on demand was bad history of previous experience $(60 \%)$ followed by fear of pain in $50 \%$ of cases. There was statistical significant difference between both groups in only two causes; fear of pelvic floor injuries (50\% in multipara vs. $20 \%$ in primipara, $\mathrm{p}=0.02$ ) and bad history of previous experience ( $60 \%$ in multipara vs. $0 \%$ in primipara, $\mathrm{p}=0.001)$. Other causes were not statistically different.

Conclusions: The incidence of cesarean sections performed on request without medical indications is rising. The reasons for this are not only for perceived medical benefit, but also due to social, cultural, and psychological factors.

Keywords: Cesarean on demand, Cesarean section, Delivery, Egypt

\section{INTRODUCTION}

Cesarean section (CS) on demand is defined as a primary CS performed on the mother's request in order to avoid a vaginal birth, without any recognized medical or obstetric indication for the procedure. The medical field now acknowledges a patient's right to actively participate in her choice of medical treatments, including method of delivery. ${ }^{1}$ There are many reasons for a cesarean section on demand: fear of delivery, fear of pain, family pressure, a previous bad experience, more control over events, improved care, and maintaining the integrity of the pelvic floor. No serious study has demonstrated an increase in maternal mortality with recourse to CS on demand. ${ }^{1}$ With the implementation of prophylactic antibiotic therapy, prophylactic heparin therapy, and the sequential use of support hose, the risk of maternal morbidity with a planned CS is the same as with a planned vaginal delivery. ${ }^{2}$ The risk of maternal hemorrhage associated with uterine atony increases with vaginal delivery whether or not labour is induced, with placenta retention, and with emergency cesarean. These risks can be avoided 
with a planned CS. ${ }^{1}$ The integrity of the pelvic floor is of great importance for active women. They want to be able to continue to exercise without any restrictions. They want to preserve sexual function. Planned cesareans offer this assurance. ${ }^{2}$ A mother is also protecting her child through a CS on demand. How better to prevent the transmission of perinatal infections such as herpes, hepatitis, HIV, human papillomavirus, or group B streptococcus than by performing a CS before the rupture of membranes. By planning a CS between the $39^{\text {th }}$ week and the $40^{\text {th }}$ week, it should be possible to reduce the risk of in utero death substantially because we know that this risk increases over the term of a pregnancy. The absence of labour would result in a decrease in the complications associated with vaginal delivery, such as the risk of intracerebral hemorrhage, shoulder dystocia, brachial plexus injury, fracture of the arm or clavicle, central nervous system depression, and asphyxia. ${ }^{3}$ Fear of pain is often an important factor in a patient's choosing to have a cesarean section. The patient might be afraid of labour and of not receiving pain relief when she wants it. ${ }^{4}$ With a planned CS, she will have those precious moments, which will take place during the day, in a calm setting, with staff that are rested and attentive to her needs. An emergency cesarean is a traumatizing experience for the mother, with the risk of postpartum depression and posttraumatic stress disorder. ${ }^{5}$ A study has yet to demonstrate that a cesarean is more painful than a vaginal delivery with regard to postpartum pain. The costs incurred for a cesarean section on demand are the same as those incurred for a vaginal delivery with oxytocin. ${ }^{6} \mathrm{CS}$ on demand will enable hospitals to improve their management of operating time and staff. In the longer term, the costs associated with surgeries for urinary incontinence, prolapse, and reconstruction of the perineum and vagina will be lower. Decreasing the number of emergency cesareans means decreasing the risk of accidents and unfortunate incidents. It means decreasing the cost of care for children with sequelae related to childbirth and the cost of lawsuits.

The current study aims to evaluate the prevalence of CS on demand in Women's health hospital, Assiut University and Abnob Central Hospital in Assiut Governorate, Egypt.

\section{METHODS}

This was a cross sectional study carried out at Assiut Women Health Hospital and Abnob Central Hospital from January 2017 to December 2017. It included two groups (group I) in the Assiut Women Health Hospital: the total number of cesarean section that done was 6741 cases and there is no CS on demand was performed because it is tertiary hospital that received emergency cases that have medical and obstetric indications and (group II) in Abnob central hospital: the total number of cesarean section that done was 180 cases and the number of CS on demand was 64 (35.6\%).

\section{Inclusion criteria}

- Accepting to participate in the study

- All pregnant women undergoing CS in the period of the study.

\section{Exclusion criteria}

- All pregnant women undergoing CS due to medical or obstetric indication.

- Caesarean hysterectomy.

The demographic data were collected by one of the study investigators. Women were asked about the causes of requesting CS before surgery. The proposal was reviewed by the Institutional Review Board (IRB) of Faculty of Medicine Assiut University and approval of Women's Health Hospital was obtained. All data were confidential and not used except for research purposes.

\section{Statistical analysis}

Data entry and data analysis were done using SPSS version 21 (Statistical Package for Social Science). Data were presented as mean and standard deviation. Chisquare and Fisher Exact tests were used to compare between qualitative variables. Independent samples t-test was used to compare between two quantitative variables. $\mathrm{P}$-value considered statistically significant when $\mathrm{P}<0.05$.

\section{RESULTS}

The study group was 64 women with age ranging from 18-40 years old, 40 primipara and 24 multipara.

Table 1: Demographic and obstetric criteria of patients underwent $\mathrm{CS}$ on demand.

\begin{tabular}{|l|l|}
\hline Variables & $n=64$ \\
\hline Age groups (years) & $42(65.6 \%)$ \\
\hline $18-25$ & $18(24.9 \%)$ \\
\hline $26-36$ & $4(9.5 \%)$ \\
\hline$>36$ & \\
\hline Residence & $19(45.2 \%)$ \\
\hline Rural & $35(54.8 \%)$ \\
\hline Urban & \\
\hline Level of education & $7(10.9 \%)$ \\
\hline Elementary school & $27(42.1 \%)$ \\
\hline High school & $30(47 \%)$ \\
\hline University level & \\
\hline Parity & $40(62.5 \%)$ \\
\hline Primapara & $24(37.5 \%)$ \\
\hline Multipara & $21 / 24(87.5 \%)$ \\
\hline Mode of previous delivery in multipara \\
\hline Vaginal & $3 / 24(12.5 \%)$ \\
\hline Cesarean section (emergency) & $26(40.6 \%)$ \\
\hline History of previous abortion & \\
\hline
\end{tabular}


Of those 24 women, 21 of them previously delivered vaginally and only 3 women delivered by emergency CS. Twenty- six women had a history of previous abortion (Table 1).

Fear of pain was the main cause for CS on demand in the whole study participants $(57.8 \%)$. In primipara, the main cause for requesting $\mathrm{CS}$ is fear of pain in $62.5 \%$ of participants followed by fear on the baby in $45 \%$ of women. On the other hand, in multipara, the main cause for CS on demand was bad history of previous experience $(60 \%)$ followed by fear of pain in $50 \%$ of cases.

There was statistical significant difference between both groups in only two causes; fear of pelvic floor injuries (50\% in multipara vs. $20 \%$ in primipara, $\mathrm{p}=0.02$ ) and bad history of previous experience $(60 \%$ in multipara vs $0 \%$ in primipara, $\mathrm{p}=0.001)$. Other causes were not statistically different.

Table 2: Causes of CS on demand in the study participants.

\begin{tabular}{|l|l|l|l|l|}
\hline Causes & All women (n=64) & Primapara (n=40) & Multipara (n=24) & P value \\
\hline Fair of pain & $37(57.8 \%)$ & $25(62.5 \%)$ & $12(50 \%)$ & 0.22 \\
\hline Fear on the baby & $25(39 \%)$ & $18(45 \%)$ & $7(29.2 \%)$ & 0.38 \\
\hline Family and husband pressure & $23(36 \%)$ & $15(37.5 \%)$ & $8(33.3 \%)$ & 0.09 \\
\hline Fear of pelvic floor injuries & $20(31.3 \%)$ & $8(20 \%)$ & $12(50 \%)$ & $0.02 *$ \\
\hline Bad history of previous experience & $15(23.4 \%)$ & 0 & $15(60 \%)$ & $0.01 *$ \\
\hline Fatigue & $4(6.3 \%)$ & 0 & $4(16.7 \%)$ & 0.23 \\
\hline
\end{tabular}

Data were expressed in form frequency (percentage). *P value was significant if $<0.05$

\section{DISCUSSION}

Present study was performed in period between June 2017 and June 2018. During this period 180 cesarean section was done; 64 (35.6\%) of them was done based on demand while emergency indication of cesarean section presented in $116(64.4 \%)$ women. In Das et al study, the prevalence of CS on demand was only $10.7 \%$. In the United Kingdom and in the North of Europe the prevalence varies from $6 \%$ to $8 \%$, in the United States $11.2 \%$, while in Australia 17.2\%. ${ }^{7}$

Al Rowaily et al, reported a total of 22,595 deliveries from 2008 to 2011, 4,305 deliveries were CS deliveries (19.05\%) and CS on demand representing $10.1 \%$ of cases. $^{8}$

The greater preference for CS was among primipara more than multipara. However, many previous studies reported that the greater preference for CS among multiparas more than nulliparas as in Das et al study (primaparas $12.4 \%$ vs multiparas $17.6 \%$ ) and Hildingsson et al study (primiparas $7.2 \%$ vs multiparas $8.9 \%)^{7,9}$

According to the result of this study it seems that the educational level of women can probably be one of the factors that may affect the women's preference for $\mathrm{CD}$, $47 \%$ of this studied woman completed their education till university so authors observed a positive relation between the women's preference for $\mathrm{CD}$ and their educational level. Similarly, in Das et al study, the prevalence of CS on demand was substantially higher among mothers with higher schooling level. ${ }^{7}$
In this study, the most frequent causes in all women were fear of pain, fear on child and family and husband pressure in $37(57.8 \%), 25(39 \%)$ and 23 (36\%) women respectively. Karlstrom et al study reported that the most frequent causes that women prefer CS is the safest option for the infant $78(7.3 \%)$, least affect her future sex life 21 $(8.7 \%)$, pain free as possible $41(10.9 \%)$ that will reduce the risk of incontinence in $50(7.4 \%)$ of participants. ${ }^{10}$

Fear of delivery in some studies reported as an effective factor in women's preference for CD as Fuglenes et al, Fenwick et al studies that reported that the main reason for a woman's request for a CS on non-medical grounds was fear of childbirth. ${ }^{11,12}$

In this study, the most frequent causes of CS on demand in multiparous women were bad history of previous experience, fear of pain, and fear on pelvic floor presented on $15(60 \%), 12(50 \%)$ and $12(50 \%)$ women respectively. Similarly, Hildingsson et al study reported that in multiparous women the causes of CS on demand were fear of giving birth and a negative experience of the previous birth. ${ }^{9}$

\section{CONCLUSION}

In conclusion, the incidence of cesarean sections performed on request without medical indications is rising. The reasons for this are not only for perceived medical benefit, but also due to social, cultural, and psychological factors. Despite dramatic improvements in the safety of anesthesia and surgery, mortality and morbidity are greater in elective cesarean sections 
compared to vaginal deliveries. An association exists between pelvic floor damage and childbirth, but this cannot be attributed entirely to vaginal deliveries and does occur even after a cesarean birth. In dealing with requests for cesarean sections, obstetricians should establish the reasons for the request and provide clear, unbiased information based on the best available evidence. Individualized modifications to the management of labor may allow some women to have vaginal deliveries. A second opinion from a colleague may help the patient to reconsider the request and make a more informed choice.

\section{Funding: No funding sources}

Conflict of interest: None declared

Ethical approval: The study was approved by the Institutional Ethics Committee

\section{REFERENCES}

1. Duperron L. Should patients be entitled to cesarean section on demand?: Yes. Canadian Family Physician. 2011;57(11):1246-8.

2. Hannah ME, Hannah WJ, Hewson SA, Hodnett ED, Saigal S, Willan AR, et al. Planned caesarean section versus planned vaginal birth for breech presentation at term: a randomised multicentre trial. Lancet. 2000;356(9239):1375-83.

3. Towner D, Castro MA, Eby-Wilkens E, Gilbert WM. Effect of mode of delivery in nulliparous women on neonatal intracranial injury. New England $\mathrm{J}$ Med. 1999;341(23):1709-14.

4. Shaaban OM, Abbas AM, Mohamed RA, Hafiz HA. Lack of pain relief during labor is blamable for the increase in the women demands towards cesarean delivery: a cross-sectional study. Facts Views Vision Obstey Gynecol. 2017;9(4):175.

5. Fisher J, Astbury J, Smith A. Adverse psychological impact of operative obstetric interventions: a prospective longitudinal study. Aus New Zealand J Psych. 1997;31(5):728-38.

6. Bost BW. Cesarean delivery on demand: what will it cost? Am J Obstet Gynecol. 2003;188(6):1418-23.

7. Das A. Cesarean delivery on maternal request. Saudi J Health Sci. 2013;2(3):141.

8. Al Rowaily MA, Alsalem FA, Abolfotouh MA. Cesarean section in a high-parity community in Saudi Arabia: clinical indications and obstetric outcomes. BMC Preg Childbirth. 2014;14(1):92.

9. Hildingsson I, Rådestad I, Rubertsson C, Waldenström U. Few women wish to be delivered by caesarean section. BJOG. 2002;109(6):618-23.

10. Karlström A, Nystedt A, Johansson M, Hildingsson I. Behind the myth-few women prefer caesarean section in the absence of medical or obstetrical factors. Midwifery. 2011;27(5):620-7.

11. Fuglenes D, Aas E, Botten G, Øian P, Kristiansen IS. Why do some pregnant women prefer cesarean? The influence of parity, delivery experiences, and fear. Am J Obstet Gynecol. 2011;205(1):45-e1.

12. Fenwick J, Staff L, Gamble J, Creedy DK, Bayes S. Why do women request caesarean section in a normal, healthy first pregnancy? Midwifery. 2010;26(4):394-400.

Cite this article as: Zakherah MS, Farghaly TA, Ahmed ES, Abbas AM. Prevalence of cesarean section on demand in Assiut Governorate, Egypt. Int J Reprod Contracept Obstet Gynecol 2019;8:1223-6. 